\title{
An RDB to RDF Mapping System Considering Semantic Relations of RDB Components
}

\author{
Hajung Sung ${ }^{+} \cdot$ Jangwon Gim ${ }^{++} \cdot$ Sukhoon Lee $^{+++} \cdot$ Doo-Kwon Baik ${ }^{++++}$
}

\begin{abstract}
For the expansion of the Semantic Web, studies in converting the data stored in the relational database into the ontology are actively in process. Such studies mainly use an RDB to RDF mapping model, the model to map relational database components to RDF components. However, pre-proposed mapping models have got different expression modes and these damage the accessibility and reusability of the users. As a consequence, the necessity of the standardized mapping language was raised and the W3C suggested the R2RML as the standard mapping language for the RDB to RDF model. The R2RML has a characteristic that converts only the relational database schema data to RDF. For the same reasons above, the ontology about the relation data between table name and column name of the relational database cannot be added. In this paper, we propose an RDB to RDF mapping system considering semantic relations of RDB components in order to solve the above issue. The proposed system generates the mapping data by adding the RDFS attribute data into the schema data defined by the R2RML in the relational database. This mapping data converts the data stored in the relational database into RDF which includes the RDFS attribute data. In this paper, we implement the proposed system as a Java-based prototype, perform the experiment which converts the data stored in the relational database into RDF for the comparison evaluation purpose and compare the results against D2RQ, RDBToOnto and Morph. The proposed system expresses semantic relations which has richer converted ontology than any other studies and shows the best performance in data conversion time.
\end{abstract}

Keywords : RDB, RDF, Semantic Web, Ontology, R2RML

\section{관계형 데이터베이스 구성 요소의 의미 관계를 고려한 $\mathrm{RDB}$ to $\mathrm{RDF}$ 매핑 시스템}

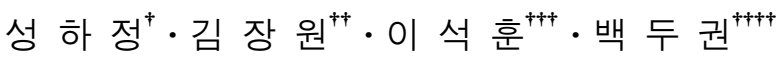

\begin{abstract}
요
약

시맨틱 웹의 확산을 위해 관계형 데이터베이스에 저장된 데이터를 온톨로지로 변환하는 연구가 활발히 진행 중이다. 관계형 데이터베이스에 저장된 데이터를 온톨로지로 변환하기 위한 연구들은 관계형 데이터베이스의 구성 요소와 $\mathrm{RDF}$ 구성 요소를 매핑하는 방식인 $\mathrm{RDB}$ to $\mathrm{RDF}$ 매 핑 모델을 주로 사용한다. 하지만 지금까지 제안된 매핑 모델들은 그 표현방식이 서로 다르며, 이는 사용자의 접근성과 재사용성을 떨어트린다. 이로 인해 표준화된 매핑 언어의 필요성이 대두되었으며, $\mathrm{W} 3 \mathrm{C}$ 에서는 $\mathrm{RDB}$ to $\mathrm{RDF}$ 모델의 표준 매핑 언어로서 $\mathrm{R} 2 \mathrm{RML}$ 을 제안하였다. $\mathrm{R} 2 \mathrm{RML}$ 은 관계형 데이터베이스 스키마 정보만을 $\mathrm{RDF}$ 로 변환하는 특징을 가진다. 이와 같은 이유로 관계형 데이터베이스의 테이블 명, 컬럼 명 사이 의 관계정보에 대한 온톨로지를 추가할 수 없다. 이 논문에서는 이러한 문제를 해결하기 위해 관계형 데이터베이스 구성 요소의 의미 관계를 고려한 $\mathrm{RDB}$ to $\mathrm{RDF}$ 매핑 시스템을 제안한다. 제안 시스템은 $\mathrm{R} 2 \mathrm{RML}$ 에서 정의한 관계형 데이터베이스의 스키마 정보에 $\mathrm{RDFS}$ 속성 정보를 확장하여 매핑 정보를 생성한다. 이러한 매핑 정보는 관계형 데이터베이스에 저장된 데이터를 RDFS 속성 정보가 포함된 RDF로 변환시킨다. 이 논문에서는 제안 시스템을 자바 기반의 프로토타입으로 구현하며, 비교 평가를 위해 관계형 데이터베이스에 저장된 데이터를 RDF로 변환하 는 실험을 수행하고 결과를 D2RQ, RDBToOnto, Morph와 비교한다. 제안 시스템은 다른 연구들에 비해 변환한 온톨로지가 풍부한 의미관계를 표현하며, 데이터 변환 시간에서 가장 우수한 성능을 보인다.
\end{abstract}

키워드 : 관계형 데이터베이스, RDF, 시맨틱 웹, Ontology, R2RML

※ 이 논문은 2013년도 정부(미래창조과학부)의 재원으로 한국연구재단-차 세대정보 - 컴퓨팅기술개발사업의 지원을 받아 수행된 연구임(No.2012MBC4A7033346).

† 준 회 원 : 고려대학교 컴퓨터·전파통신공학과 석사과정

†† 준 회 원 : 한국과학기술정보연구원 선임연구원

††† 준 회 원 : 고려대학교 컴퓨터·전파통신공학과 박사과정

왜 종신회원 : 고려대학교 융합소프트웨어전문대학원 교수 논문접수:2013년 9월 27일

수 정 일 : 1 차 2013년 12월 4일

심사완료 : 2013년 12월 11일

* Corresponding Author:Doo-Kwon Baik(baikdk@korea.ac.kr)

\section{1. 서 론}

웹 온톨로지 언어를 사용하는 시맨틱 웹의 영향으로 온톨 로지의 사용이 증가하고 있다. 또한 이를 저장하고 관리하기 위한 온톨로지 저장소에 대한 연구가 진행되고 있다[1-7]. 온톨로지 저장소는 $\mathrm{RDF}$ 형태의 그래프 모델을 표현하기 위한 
데이터 구조를 가진다. 이러한 데이터 구조는 대부분 관계 형 데이터베이스에 저장된 데이터 구조와 다르다. 이로 인 해 시맨틱 웹에서는 관계형 데이터베이스 기반의 웹 페이지 에 저장된 데이터를 검색할 수 없는 문제를 가진다. 하지만 위와 같은 문제로 인해 시맨틱 웹에서 기존 윕 페이지에 저 장된 데이터를 사용하지 않는 것은 시맨틱 웹의 확산을 막 는 다른 문제를 발생시킨다. 따라서 시맨틱 웹에서도 기존 웹 페이지에 저장된 데이터를 사용하는 방법에 대한 연구의 필요성이 증가하였다.

이러한 연구들은 관계형 데이터베이스에 저장된 데이터를 온톨로지로 변환하는 방법에 대한 것이 대부분이다. 관계형 데이터베이스에 저장된 데이터를 $\mathrm{RDF}$ 형태의 온톨로지로 변환하기 위해서는 주로 매핑 방식을 이용한다[8,9]. 또한 매 핑 규칙을 표현하기 위해 다양한 매핑 언어들도 제안되고 있다. DB2OWL은 매핑을 구현하기 위하여 R2O 언어를 개 발하였으며[10], D2RQ의 경우에는 자체적으로 정의한 언어 를 사용한다[11]. 하지만 다양한 매핑 언어의 사용은 매핑 언어에 대한 접근성과 재사용성을 떨어뜨린다.

위와 같은 문제를 해결하기 위해 $\mathrm{W} 3 \mathrm{C}$ 에서는 표준화된 매 핑 언어인 R2RML을 제안 하였다[12]. Morph와 DB2Triple는 $\mathrm{R} 2 \mathrm{RML}$ 에서 정의한 매핑 규칙을 사용하여 관계형 데이터베 이스에 저장된 데이터를 $\mathrm{RDF}$ 형태의 온톨로지로 변환한다 [13,14]. 하지만 R2RML은 관계형 데이터베이스의 스키마 정 보만을 $\mathrm{RDF}$ 형태의 온톨로지로 변환한다. 따라서 외부에 존재하는 테이블 및 컬럼과 내부의 테이블 및 컬럼 사이의 관계 정보를 표현하지 않는다. 또한 외래 키(Foreign Key) 로 정의되지 않은 테이블 사이의 관계 정보에 대해서도 정 의하지 못하여 온톨로지를 확장하는데 제약이 따른다. 이러 한 문제점은 테이블 명과 컬럼 명 사이의 관계 정보를 온토 롤지로 표현하여 해결한다. 따라서 R2RML에 관계형 데이 터베이스의 테이블 명, 컬럼 명 사이에 관계 정보를 표현하 기 위한 매핑 규칙 정의와 확장이 필요하다.

이러한 문제점을 개선하기 위해 이 논문은 관계형 데이터 베이스 구성 요소의 의미 관계를 고려한 $\mathrm{RDB}$ to $\mathrm{RDF}$ 매핑 시스템을 제안한다. 제안 시스템은 표준화된 매핑 언어인 $\mathrm{R} 2 \mathrm{RML}$ 을 사용하며 $\mathrm{RDFS}$ 속성 정보를 매핑 모델에 추가 한다. 추가된 $\mathrm{RDFS}$ 속성 정보는 관계형 데이터베이스에 정 의된 관계 정보를 표현한다. 제안 시스템은 최종적으로 $\mathrm{RDF}$ 의 클래스 및 속성으로 변환된 온톨로지를 표현한다. 또한 변환된 온톨로지는 온톨로지 저장소에 저장되며 $\mathrm{SPARQL}$ 질의문을 통하여 온톨로지를 검색할 수 있다.

이 논문의 구성은 다음과 같다. 제 2 장에서는 관계형 데이 터베이스를 $\mathrm{RDF}$ 형태의 온톨로지로 변환하기 위한 $\mathrm{RDB}$ to $\mathrm{RDF}$ 변환에 관련된 연구 내용을 기술하며, 제 3 장에서는 제안 시스템의 구조를 설명한다. 제4장에서는 제안 시스템 의 구현 환경 및 방법에 관하여 기술하며, 제 5 장에서는 제 안 시스템 검증을 위한 실험 결과 및 기존 연구와의 비교 평가를 보인다. 마지막으로 제6장에서는 결론에 관해 기술 한다.

\section{2. 관련 연구}

이 장에서는 관계형 데이터베이스를 $\mathrm{RDF}$ 형태의 온톨로 지로 변환하는 연구의 필요성과 방법에 대해서 기술한다. 또한 기존 연구에서 제안된 매핑 모델에 대해서 논하며 $\mathrm{R} 2 \mathrm{RML}$ 을 매핑 언어로 사용하는 연구에 관해서 기술한다.

\subsection{RDB2RDF}

기존의 관계형 데이터베이스에 저장된 데이터를 $\mathrm{RDF}$ 형 태의 온톨로지로 변환하기 위한 방식으로 관계형 데이터베 이스의 구성요소와 $\mathrm{RDF}$ 의 구성요소를 매핑 하는 연구가 이 루어졌다. $\mathrm{RDB} 2 \mathrm{RDF}$ 는 관계형 데이터베이스의 테이블을 $\mathrm{RDF}$ 의 클래스로 매핑 하며 컬럼 및 속성은 $\mathrm{RDF}$ 의 속성으 로 매핑 한다[8,9]. 이러한 매핑 규칙에 따라 관계형 데이터 베이스에 저장된 데이터를 $\mathrm{RDF}$ 형태의 온톨로지로 변환한 다. $\mathrm{RDB} 2 \mathrm{RDF}$ 에서 매핑은 구현 방식에 따라 정적, 동적 구 현으로 구분된다. 정적 구현 방식은 매핑 규칙을 사용하여 관계형 데이터베이스에 저장된 데이터를 $\mathrm{RDF}$ 로 변환한다. 정적 구현 방식의 변환은 구현이 쉽지만, 변화가 많은 데이 터에는 적합하지 않다는 문제를 가진다. 동적 구현 방식은 $\mathrm{SPARQL}$ 질의문을 $\mathrm{SQL}$ 로 변환하는 방식을 통해 관계형 데 이터베이스에 저장된 데이터를 검색한다[15,16,17]. 이는 관 계형 데이터베이스에 저장된 데이터를 실시간으로 얻어올 수 있으므로 데이터의 최신성을 보장한다. 하지만 동적 방 식은 질의문의 완전한 변환이 어려우므로 질의 처리 성능이 떨어지는 문제를 가진다.

\section{$2.2 \mathrm{D} 2 \mathrm{RQ}$}

$\mathrm{D} 2 \mathrm{RQ}$ 는 매핑을 이용하여 관계형 데이터베이스에 저장된 데이터를 $\mathrm{RDF}$ 형태의 온톨로지로 변환하는 대표적인 연구 이다. $\mathrm{D} 2 \mathrm{RQ}$ 는 자체적으로 개발한 매핑 언어를 사용한다. $\mathrm{D} 2 \mathrm{RQ}$ 의 매핑 언어는 $\mathrm{D} 2 \mathrm{R}$ 에서 얻은 경험을 토대로 생성되 었다[18]. 매핑 언어에 따라 관계형 데이터베이스에 접근하 여 스키마 정보에 대한 매핑 정보를 자동으로 생성한다. 자 동으로 생성된 매핑 정보는 관계형 데이터베이스의 기본적 인 정보만 가지고 있다. 따라서 사용자는 기본 키(Primary $\mathrm{Key}$ )와 외래 키(Foreign Key)및 조인 관계에 대한 정보를 추가로 입력한다. 입력된 정보를 사용하여 풍부한 의미를 표현하여 자동 생성의 한계를 극복한다. D2RQ 서버는 생성 된 매핑 정보를 참고하여 관계형 데이터베이스의 데이터를 $\mathrm{RDF}$ 형태의 온톨로지로 변환한다. 변환된 데이터는 시스템 의 메모리에 $\mathrm{RDF}$ 형태의 온톨로지로 생성된다. 이렇게 생 성된 데이터는 SPARQL을 통해 검색할 수 있다[19]. 또한 $\mathrm{D} 2 \mathrm{RQ}$ 는 매핑 정보를 참고하여 $\mathrm{SPARQL}$ 을 $\mathrm{SQL}$ 로 변환한 다[20]. 질의문의 변환에 의한 매핑 모델은 데이터의 최신성 을 보장하며 추가적인 트리플 저장소가 필요하지 않은 장점 이 있다. 하지만 $\mathrm{D} 2 \mathrm{RQ}$ 의 질의문 변환은 조인 관계를 매핑 정보에 정의하지 않았을 때는 변환을 지원하지 않는다. $\mathrm{D} 2 \mathrm{RQ}$ 는 동일한 컬럼 명에 대한 $\mathrm{URI}$ 를 테이블 별로 다르게 
지정해야 한다. 따라서 두 개 이상 존재하는 동일한 컬럼 명을 검색하는 SPARQL 질의문의 결과값이 하나의 컬럼 명 에 대한 결과값을 갖는 문제점이 있다. 마지막으로 $\mathrm{D} 2 \mathrm{RQ}$ 는 표준화된 매핑 언어를 사용하지 않아 매핑 언어에 대한 재 사용성과 접근성이 낮다. 이는 매핑 언어의 학습에 들어가 는 비용을 높인다.

\subsection{RDBToOnto}

RDBToOnto는 관계형 데이터베이스에 저장된 데이터를 온톨로지로 변환하는 연구로서 $\mathrm{TAO}$ 프로젝트에서 진행 하 였다[21]. 데이터 변환 방식은 관계형 데이터베이스의 테이 블 및 컬럼에 대한 스키마 정보만을 온톨로지로 변환한다. $\mathrm{RDBToOnto}$ 는 관계형 데이터베이스에 저장된 데이터의 의 미를 표현하기 위해 RTAXON 학습 방법을 이용하여 자동 분류를 지원한다[22]. RTAXON에 정의된 규칙에 따라 카테 고리에 관련된 어휘를 가지고 있는 단어에 대해 subClassOf 관계를 자동으로 지원한다. 추가적으로, RDBToOnto는 사용 자 정의에 의한 제약 조건을 추가, 데이터 중복을 방지를 위한 정규화 기능, 편리한 $\mathrm{UI}$ 를 제공한다. RDBToOnto는 정 적 구현 방식으로 데이터의 최신성을 보장하지 않는다. 그 리고 데이터 변환을 위해 추가적인 변환 시간이 필요하므로 대용량의 데이터 처리에는 적합하지 않다. RDBToOnto는 표준화된 매핑 언어를 사용하지 않는다. 또한 관계형 데이 터베이스의 테이블 명, 컬럼 명 사이에 관계 정보를 표현하 기 위한 온톨로지로 추가하는 데는 제약을 가진다.

\subsection{R2RML}

$\mathrm{W} 3 \mathrm{C}$ 의 $\mathrm{RDB} 2 \mathrm{RDF}$ 워킹 그룹에서는 매핑 언어의 표준화 를 위하여 R2RML을 제안하였다. R2RML은 관계형 데이터 베이스의 테이블, 뷰, $\mathrm{SQL}$ 질의문으로 이뤄진 데이터에 대 한 매핑을 지원한다. R2RML은 트리플사상(LogicalTable)을 최상단 노드로 하며 하위 노드에 논리테이블(LogicalTable), 주어사상(SubjectMap), 술어목적어사상(PredicateObjecMap) 노드를 가진다. 각 테이블 정보는 트리플사상에 매핑 되며 논리테이블 노드는 테이블, 뷰, $\mathrm{SQL}$ 질의문에 대한 정보를 표현한다. 주어사상은 $\mathrm{RDF}$ 변환된 데이터의 주어(Subject) 를 표현하며 rr:template을 사용하여 주어의 속성을 나타낸 다. 이 때 rr:template 값은 기본 키의 컬럼 명을 포함하여 표현한다. rr:template에 포함된 기본 키의 컬럼 명은 기본 키의 데이터 값으로 변환되어 주어를 구성한다. 술어목적어 사상은 술어(Predicate)와 목적어(Object)의 값을 설정한다. 이 때 술어에는 $\mathrm{RDF}$ 의 술어 정보를 표현하며 목적어사상 (ObjectMap)에 $\mathrm{RDF}$ 의 목적어 정보를 표현한다. 목적어사상 은 컬럼 값을 표현하기도 하지만 rr:template 을 사용하여 특정 컬럼 값을 표현할 수도 있다. 참조목적어사상(RefObjectMap)은 테이블간의 조인 관계를 표현한다. 즉, 참조목적어사상을 이 용하여 조인 관계가 설정된 테이블간에 컬럼 값을 표현한 다. 마지막으로 그래프사상(GraphMap)은 주어사상과 술어 목적어사상에 포함되어 $\mathrm{RDF}$ 의 그래프를 표현한다.

\subsection{Morph}

$\mathrm{Morph}$ 는 $\mathrm{W} 3 \mathrm{C}$ 에서 제안한 $\mathrm{R} 2 \mathrm{RML}$ 을 구현하여 관계형 데이터베이스에 저장된 데이터를 $\mathrm{RDF}$ 형태의 온톨로지로 변환하는 연구이다[13]. Morph는 자바 기반 시스템으로 구 성되어 있으며 수동으로 매핑 정보를 생성한다. 매핑 구현 방식은 정적 방식을 사용하며 매핑 규칙은 R2RML의 정의 에 따른다. R2RML의 정의에 따라 트리플사상 노드는 관계 형 데이터베이스의 테이블과 $1: 1$ 대응된다. 트리플사상 노드 의 하위 노드인 논리테이블, 주어사상, 술어목적어사상 노드 를 사용하여 트리플사상에 정의된 테이블 명과 컬럼 명 정 보를 표현한다. 또한 참조목적어사상을 이용하여 테이블 간 조인 관계를 표현한다. Morph는 표준화된 매핑 언어를 사용 한다. 따라서 매핑 언어에 대한 접근성과 재사용성이 높다. 하지만 Morph는 R2RML에 정의된 관계형 데이터베이스 스 키마 정보만을 $\mathrm{RDF}$ 형태의 온톨로지로 변환한다. 따라서 관계형 데이터베이스에 테이블 명과 컬럼 명 사이의 관계 정보를 표현하는데 제약이 따른다.

\subsection{DB2Triple}

$\mathrm{DB} 2 \mathrm{Tripe}$ 은 $\mathrm{W} 3 \mathrm{C}$ 에서 제안한 $\mathrm{R} 2 \mathrm{RML}$ 과 다이렉트 매핑 표준을 이용하여 관계형 데이터베이스에 저장된 데이터를 $\mathrm{RDF}$ 형태의 온톨로지로 변환한다[14]. DB2Triple은 RDB2RDF 워킹 그룹에서 검증을 받았으며 Antidot 사에서 자바 기반 의 오픈 소스 형태로 제공하고 있다. 매핑 정보는 수동으로 생성하며 R2RML에서 정의한 매핑 규칙을 따른다. 따라서 트리플사상을 이용하여 관계형 데이터베이스의 테이블 정보 를 표현한다. 매핑 구현 방식은 정적 방식을 사용하며 이는 실시간 변경 점이 많은 데이터에 대한 사용에 제약을 가진 다. DB2Triple은 표준화된 매핑 언어인 R2RML을 사용하여 시스템 독립적인 매핑 언어를 사용하는 장점이 있다. 하지 만 R2RML은 관계형 데이터베이스의 스키마 정보만을 $\mathrm{RDF}$ 형태의 온톨로지로 변환한다. 따라서 DB2Triple은 관계형 데이터베이스의 테이블 명, 컬럼 명 사이의 관계정보는 변환 하지 않는다. 또한 사용하기 편리한 UI를 제공하지 않아 자바 라이브러리 파일을 사용자가 추가해야 하는 문제점을 가진다.

관계형 데이터베이스에 저장된 데이터를 $\mathrm{RDF}$ 형태의 온 톨로지로 변환하는 연구의 필요성에 따라 많은 연구들이 진 행되었다. $\mathrm{D} 2 \mathrm{RQ}$ 와 $\mathrm{RDBT}$ oOnto는 $\mathrm{RDB}$ to $\mathrm{RDF}$ 매핑 모델 을 사용하는 대표적인 연구이다. 하지만 기존의 연구들은 표 준화된 매핑 언어를 사용하지 않아 매핑 언어의 접근성과 재 사용성이 떨어진다. 이러한 문제를 해결하기 위해 R2RML이 제안되었으며 R2RML을 적용한 대표적인 연구는 Morph와 $\mathrm{DB} 2$ Triple이 있다. R2RML을 적용한 연구들은 표준화된 매 핑 언어를 사용하였으나 관계형 데이터베이스의 스키마 정 보만을 $\mathrm{RDF}$ 로 변환하는 문제점을 가진다. 따라서 관계형 데이터베이스의 테이블 명, 컬럼 명 사이의 관계정보는 변 환하지 않는다. 위와 같은 문제를 해결하기 위해 이 논문은 관계형 데이터베이스 구성 요소의 의미 관계를 고려한 $\mathrm{RDB}$ 
to $\mathrm{RDF}$ 매핑 시스템을 제안한다.

\section{3. 제안 시스템}

이 장에서는 관계형 데이터베이스 구성 요소의 의미 관계 를 고려한 $\mathrm{RDB}$ to $\mathrm{RDF}$ 매핑 시스템 을 제안한다. 3.1절에 서는 제안 시스템을 간략하게 소개하고 3.1.1절에서는 시스 템 상세 구조를 설명한다. 3.1.2절에서는 이 논문에서 사용하 는 주요 표기에 대하여 정의한다. 3.1.3절에서는 $\mathrm{RDB}$ to $\mathrm{RDF}$ 매퍼, 3.1.3절에서는 R2RML 분석기, 3.1.4절에서는 $\mathrm{SQL}$ 생성기, 3.1.5절에서는 $\mathrm{RDB}$ to $\mathrm{RDF}$ 변환기를 각각 설 명한다. 마지막으로 3.2 절에서 $\mathrm{RDB}$ to $\mathrm{RDF}$ 변환 프로세스 를 기술하여 제안 시스템에 대한 설명을 마친다.

\section{1 제안 시스템 개요}

제안 시스템은 R2RML을 이용하여 관계형 데이터베이스 에 저장된 데이터를 $\mathrm{RDF}$ 형태의 온톨로지로 변환한다. 또 한 제안 시스템은 R2RML에 관계형 데이터베이스의 관계 정보들을 $\mathrm{RDFS}$ 속성으로 추가하여 변환된 온톨로지에 추 가한다. 이를 위해 $\mathrm{RDB}$ to $\mathrm{RDF}$ 매퍼, R2RML 분석기, $\mathrm{SQL}$ 생성기, $\mathrm{RDB}$ to $\mathrm{RDF}$ 변환기를 가진다. $\mathrm{RDB}$ to $\mathrm{RDF}$ 매퍼는 $\mathrm{RDB}$ 구성요소와 $\mathrm{RDF}$ 구성요소를 매핑 하는 기능 을 가진다. $\mathrm{RDB}$ to $\mathrm{RDF}$ 매퍼에서 정의한 규칙을 바탕으로 $\mathrm{R} 2 \mathrm{RML}$ 분석기는 R2RML 문서를 분석한다. R2RML을 분 석한 정보는 $\mathrm{SQL}$ 생성기에 전달되어 $\mathrm{SQL}$ 을 생성한다. 위 에서 생성된 $\mathrm{SQL}$ 질의문을 사용하여 관계형 데이터베이스 의 저장된 데이터에 접근하여 데이터를 가져온다. 마지막으 로 $\mathrm{RDB}$ to $\mathrm{RDF}$ 변환기를 통해 $\mathrm{SQL}$ 질의문을 통해 가져온 데이터를 $\mathrm{RDF}$ 형태의 온톨로지로 변환한다.

1) 제안 시스템 구조

Fig. 1은 제안 시스템 구조를 보여준다. 제안 시스템은
Fig. 1과 같이 "R2RML 분석", "SQL 생성”, "RDB to $\mathrm{RDF}$ 변환”의 세 부분으로 구성된다.

- R2RML 분석: 사용자가 입력한 R2RML 문서를 분석하 여 관계형 데이터베이스 스키마 정보를 정의한다. R2RML 은 트리플사상을 기반으로 논리테이블, 주어사상, 술어목적 어사상을 하위 노드로 가진다. 트리플사상은 하나의 테이블 에 매핑되며 논리테이블 정보를 사용하여 테이블 정보를 정 의한다. 또한 주어사상을 통해 주어에 정의할 rr:template 정 보를 정의한다. 마지막으로 술어목적어사상 정보를 사용하 여 술어와 목적어 정보를 정의한다.

- SQL 생성: R2RML 분석 단계에서 정의한 정보를 기반 으로 $\mathrm{SQL}$ 질의문을 생성한다. 트리플사상에는 관계형 데이 터베이스의 테이블 정보가 정의되어 있다. 논리테이블 정보 를 사용하여 $\mathrm{SQL}$ 질의문의 From 절을 정의한다. 다음으로 주어사상에 정의된 기본 키 정보를 활용하여 테이블의 기본 키 정보를 Select 절에 추가한다. 마지막으로 술어목적어사 상 정보를 바탕으로 컬럼 정보를 Select 절에 추가하여 $\mathrm{SQL}$ 질의문을 완성한다.

- $\mathrm{RDB}$ to $\mathrm{RDF}$ 변환: $\mathrm{RDB}$ 에 저장된 데이터를 $\mathrm{RDF}$ 로 변환하여 저장한다. $\mathrm{R} 2 \mathrm{RML}$ 을 기반으로 생성된 $\mathrm{SQL}$ 질의문 을 통해 관계형 데이터베이스에 저장된 데이터를 질의한다. $\mathrm{SQL}$ 질의문을 통해 가져온 결과는 질의결과를 관리하는 자 료구조에 저장된다. 질의 결과에 저장된 데이터는 $\mathrm{R} 2 \mathrm{RML}$ 에 저장된 정보에 사용하여 $\mathrm{RDF}$ 로 변환된다. 이때 주어는 주어사상에 저장된 정보를 사용하여 정의된다. 다음으로 술 어, 목적어는 술어목적어사상에 저장된 정보를 사용하여 정 의된다. 술어에 저장된 정보에 따라 목적어의 생성은 다음 의 방법을 따른다. 첫째 술어에 저장된 정보가 관계형 데이 터베이스의 스키마 정보이면 목적어는 관계형 데이터베이스 에 저장된 데이터가 된다. 둘째 술어에 저장된 정보가 $\mathrm{RDFS}$ 속성이면 목적어는 술어목적어사상에 정의된 정보를 따른다. 위에 방법에 따라 술어목적어사상의 정보는 술어, 목적어로
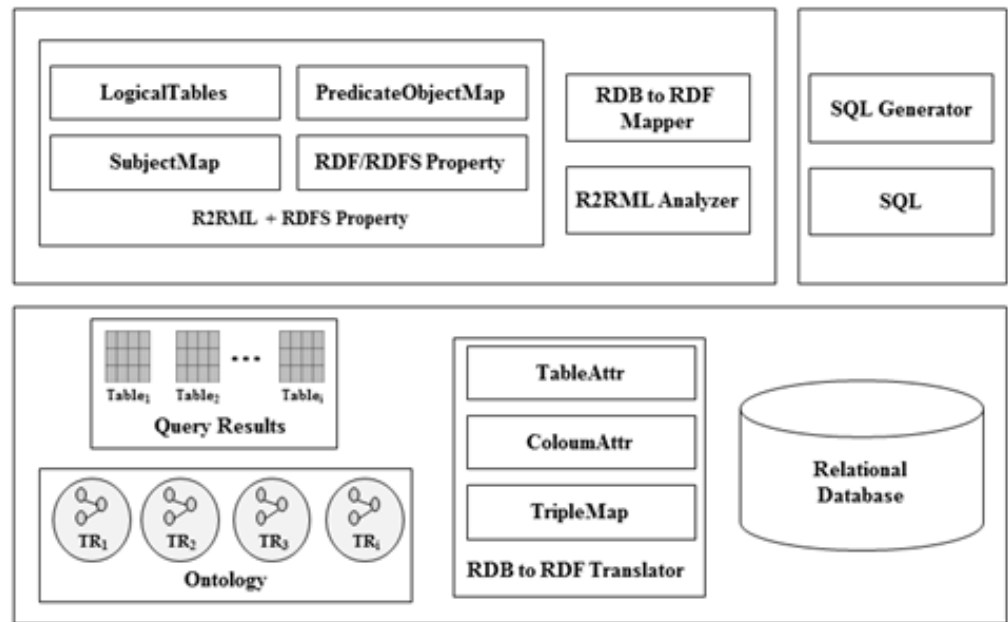

Fig. 1. System architecture 
변환된다. $\mathrm{SQL}$ 질의문을 통해 생성된 질의 결과에 대한 변 환이 완료되면 $\mathrm{RDF}$ 문서를 생성하여 변환을 완료한다.

2) 주요 표기 및 기호 정의

이 절에서는 이 논문에서 사용하는 주요 표기 및 기호 등 에 대해 정의한다. 이 논문에서 사용하는 주요 표기 및 기 호를 Table 1에 정리 한다.

\section{3) $\mathrm{RDB}$ to $\mathrm{RDF}$ 매퍼}

제안 시스템에서 제시하는 $\mathrm{RDB}$ to $\mathrm{RDF}$ 매핑 규칙은 Table 2와 같다. 관계형 데이터베이스의 구성요소를 테이블 명, 뷰 명, 컬럼 명, 기본 키, 외래 키, 인스턴스로 정의한다. 또한 $\mathrm{RDFS}$ 구성요소는 총 17 개의 속성을 매핑 대상으로 구성한다. RDFS의 속성 중 관계형 데이터베이스의 구성요 소와 매핑 가능한 속성은 type, subClassOf, subPropertyOf, objectPropertyOf, domain, range이다. 다른 속성의 경우에는 관계형 데이터베이스의 구성요소와 매핑 시킬 수가 없다.
테이블 명과 뷰 명의 경우에는 type과 매핑하며 subClassOf 속성을 사용하여 테이블 간의 상 하위 관계를 나타낸다. 마 지막으로 2 개 이상의 테이블을 연결하기 위해 사용되는 테 이블은 domain과 range로 표현될 수 있다. 따라서 domain 과 range도 테이블 명과 뷰 명으로 매핑된다. 기본 키와 외 래 키는 objectProperty를 구성하여 표현한다. 이때 술어는 컬 럼 명이 되므로 술어와 컬럼 명을 매핑 시킨다. 또한 주어는 기본 키와 외래 키로 매핑되며 인스턴스는 목적어와 매핑된 다. 컬럼 명의 경우에는 subProperty를 사용하여 컬럼 간의 상 하위 관계를 나타낼 수 있기 때문에 subProperty와 매핑 된다. subProperty를 표현하기 위해 주어와 목적어에 컬럼 명이 사용된다. 따라서 컬럼 명은 주어와 목적어로 매핑 될 수 있다. 관계형 데이터베이스의 구성요소와 직접적으로 매 핑 할 수 없는 11 개의 $\mathrm{RDFS}$ 구성요소는 사용자의 정의에 따른다. 즉 관계형 데이터베이스의 인스턴스 정보는 사용자 정의에 따라 매핑 하는 규칙을 따른다.

Table 1. Definition of Notation and Symbol

\begin{tabular}{|c|c|}
\hline Nataion/Symbol & Description \\
\hline R2RMLd & R2RML Documnet \\
\hline $\mathrm{RDF}_{\mathrm{d}}$ & RDF Documnet \\
\hline $\mathrm{TA}[]$ & A list of th definition table attributes \\
\hline $\mathrm{CA}[]$ & A list of th definition column attributes \\
\hline TM[] & A list of th definition TripleMap \\
\hline $\mathrm{RS}$ & SQL Query results \\
\hline SQLs & A select statement in $\mathrm{SQL}$ \\
\hline SQLfrom & A from statement in SQL \\
\hline SQL[] & A SQL query list \\
\hline $\operatorname{Parsing}()$ & A function for extracting TM information through to analysis a R2RML document \\
\hline SetTableAttr() & A function for definition of $\mathrm{TA}[]$ \\
\hline AddTableAttr () & A function of adding table attributes to TA[] List \\
\hline SetColumnAttr( $)$ & A function for definition of $\mathrm{CA}[]$ \\
\hline AddColumnAttr() & A function of adding column attributes to CA[] List \\
\hline SetFromstatement() & A function of defining a from statement in SQL \\
\hline SetKeyStatement() & A function of defining a primary key \\
\hline SetSelectStatement() & A function of defining a select statement in SQL \\
\hline $\operatorname{AddSQL}()$ & A function of adding SQL to SQL list \\
\hline SetTripleTemplete( $)$ & A function of confirming template information of a subjectMap \\
\hline SetSubject () & a function of defining subject \\
\hline SetPredicate() & a function of defining predicate \\
\hline SetObject() & a function of defining object \\
\hline AddRDF) & a function of adding defined RDF to RDF Document \\
\hline
\end{tabular}


Table 2. RDB to RDF Mapping rule

\begin{tabular}{c|l}
\hline $\begin{array}{c}\text { RDB } \\
\text { Component }\end{array}$ & \multicolumn{1}{|c}{ RDFS components } \\
\hline Table Name & type, subClassOf, domain, range \\
\hline View Name & type, subClassOf \\
\hline Column Name & subProperty, objectProperty \\
\hline PK Name & object Property \\
\hline FK Name & object Property \\
\hline Instance & $\begin{array}{l}\text { type, sub Class Of, sub Property Of, object } \\
\text { Property, domain, range, seeAlso, labe, is DefineBy, } \\
\text { comment, first, member, rest, values, subject, } \\
\text { predicate, object }\end{array}$ \\
\hline
\end{tabular}

4) R2RML 분석기

Table 3은 R2RML을 분석기의 알고리즘을 나타낸다. $\mathrm{R} 2 \mathrm{RML}$ 분석기는 입력 값으로 $\mathrm{R} 2 \mathrm{RMLd}$ 를 갖고 출력 값은 $\mathrm{TA}[], \mathrm{CA}[]$ 를 가진다. R2RML 분석기에 입력된 $\mathrm{R} 2 \mathrm{RMLd}$ 는 파싱 함수를 이용하여 R2RML 문서 내 트리플사상을 정 의한다. 트리플사상은 논리테이블, 주어사상, 술어목적어사상 으로 구성되며 R2RML 문서 내 정의를 따라 TM[]에 저장 된다. TM[]은 트리플사상으로 정의되며 R2RML 문서에는 한 개 이상의 트리플사상이 정의되어 있다. 따라서 $\mathrm{TM}[]$ 은 리스트 형태의 자료구조를 가진다. 파싱 함수를 통해 TM[]의 정의가 완료되면 테이블과 컬럼 정보를 정의한다. SetTableAttr 함수는 $\mathrm{TM}[]$ 에 정의된 논리테이블 정보와 주어사상 정보를 이용하여 테이블의 이름과 rr:template 정보를 정의한다. 이 렇게 정의된 테이블 정보는 $\mathrm{TA}[]$ 에 저장되며 $\mathrm{TM}[]$ 의 수만큼 정보를 가진다. 테이블 속성 정의가 완료되면 AddTableAttr 함수를 이용하여 테이블 속성 정보를 TA[] 리스트에 추가 한다. TA[] 정보가 완료되면 컬럼 속성 정보를 정의한다. 컬럼 속성은 SetColumnAttr 함수를 통해 정의된다 이 때 컬럼 속성은 $\mathrm{CA}[]$ 에 저장되며 컬럼 명과 컬럼 별칭을 정의 하며 추가적으로 $\mathrm{RDFS}$ 속성 정보를 가진다. 컬럼 속성 정 보의 정의가 완료되면 AddColumnAttr 함수를 이용하여 컬 럼 속성 정보를 $\mathrm{CA}[]$ 리스트에 추가한다.

Table 3. R2RML Analyzer

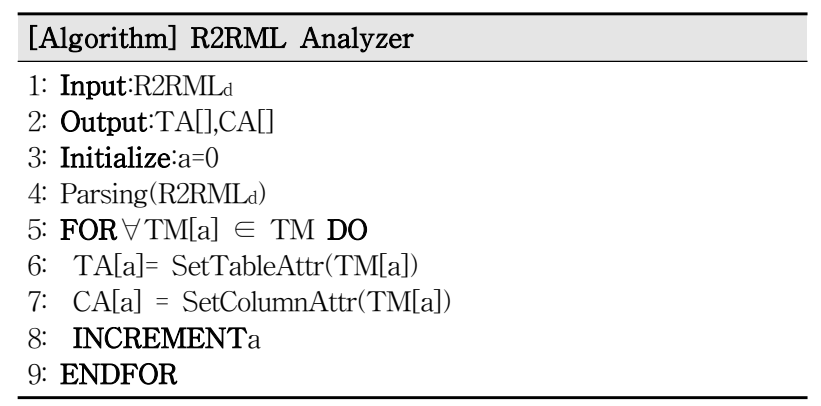

\section{5) SQL 생성기}

Table 4는 SQL 질의문을 생성하는 생성기의 알고리즘을 나타낸다. $\mathrm{SQL}$ 생성기는 $\mathrm{TA}[], \mathrm{CA}[]$ 를 입력 값을 갖고
$\mathrm{SQL}[]$ 을 출력 값으로 가진다. $\mathrm{TA}[]$ 에는 테이블 정보가 저 장되어 있다. 따라서 $\mathrm{SQL}$ 질의문은 $\mathrm{TA}[]$ 에 저장된 데이터 를 기반으로 생성된다. TA[]에 저장된 테이블 명 정보는 SetFromStatement 함수를 통해 SQL 질의문의 From 절을 생성하는데 사용된다. 이때 생성된 $\mathrm{SQL}$ 질의문은 $\mathrm{SQL}$ from에 저장된다. $\mathrm{SQL}$ 질의문의 From 절의 생성이 완료되면 테이 블의 기본 키 값을 설정한다. 테이블의 기본 키 명은 TA[] 에 저장되어 있으며 기본 키 명을 Select 절에 추가하여 기 본 키 값을 가져온다. 이렇게 설정된 기본 키 값은 주어를 정의할 때 사용된다. 기본 키 명의 정의가 완료되면 $\mathrm{TA}[]$ 에 속한 컬럼 명을 Select 절에 추가한다. 컬럼 명은 $\mathrm{CA}[]$ 에 저 장되어 있으며 $\mathrm{TA}[]$ 에 저장된 테이블 명과 $\mathrm{CA}[]$ 에 저장된 테이블 명이 일치하는 경우에만 Select 절에 추가한다. CA[] 에 저장된 컬럼 명을 Select 절에 추가하여 Select 절의 생 성을 완료한다. Select 절의 생성이 완료되면 $\mathrm{SQLs}$ 에 저장 한다. 하나의 테이블 속성에 대한 $\mathrm{SQL}$ 질의문 변환이 완료 되면 $\mathrm{SQL}_{s}$ 와 $\mathrm{SQL}$ from을 $\mathrm{SQL}[]$ 에 저장한다. 각각의 테이블 속성마다 생성된 $\mathrm{SQL}$ 질의문은 $\mathrm{SQL}[]$ 에 리스트 형태로 저 장된다.

Table 4. SQL Generator

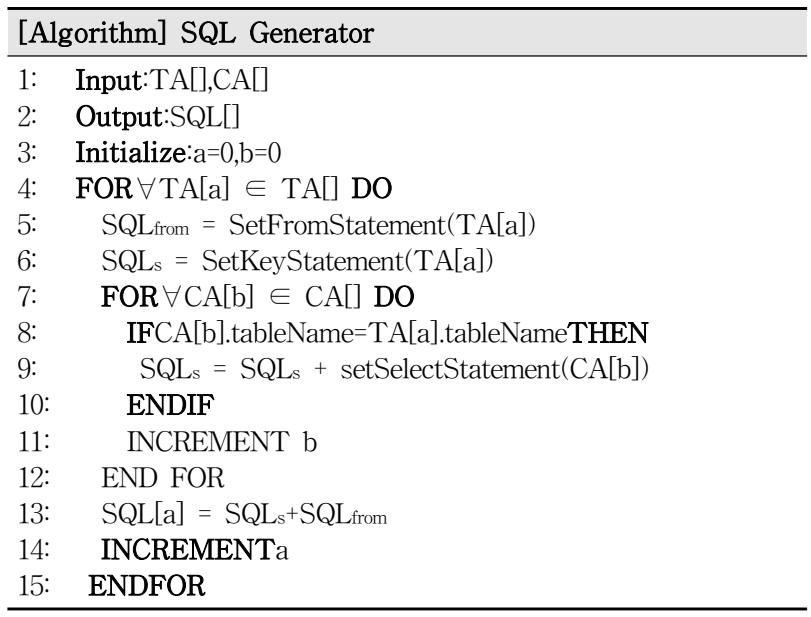

6) $\mathrm{RDB}$ to $\mathrm{RDF}$ 변환기

Table 5는 RDB to $\mathrm{RDF}$ 변환기의 알고리즘을 나타낸다. $\mathrm{RDB}$ to $\mathrm{RDF}$ 변환기는 입력 값으로 $\mathrm{TA}[], \mathrm{CA}[], \mathrm{SQL}[]$ 을 가지며 출력 값으로 $\mathrm{RDF}$ 를 가진다. 입력된 $\mathrm{SQL}$ 질의문 은 Query 함수를 통해 관계형 데이터베이스에 저장된 데이 터에 질의한다. Query 함수는 모든 $\mathrm{SQL}$ 질의문에 대한 질 의 결과를 $\mathrm{RS}$ 에 저장한다. $\mathrm{RS}$ 에 저장된 질의 결과는 각각 의 저장 데이터별로 $\mathrm{RDF}$ 로 변환된다. $\mathrm{RS}$ 의 저장된 데이터 를 $\mathrm{RDF}$ 로 변환하는 과정은 $\mathrm{TA}[]$ 에 저장된 데이터를 기반 으로 한다. TA[]에는 테이블에 대한 정보가 저장되어 있다. 따라서 $\mathrm{TA}[]$ 에 저장된 테이블 정보와 $\mathrm{RS}$ 에 저장된 테이블 정보를 확인하여 일치하는 데이터를 찾는다. 테이블 정보가 일치하면 $\mathrm{TA}[]$ 에 저장된 rr:template 정보를 참조하여 트리 
플의 주어 정보를 저장한다. 다음으로 $\mathrm{CA}[]$ 에 저장된 컬럼 정보를 사용하여 술어와 목적어 정보를 저장한다. 이때 술 어의 정보가 RDFS 속성으로 설정되어 있으면 목적어 정보 를 $\mathrm{CA}[]$ 설정된 데이터로 저장한다. 하나의 레코드에 대해 $\mathrm{RDF}$ 변환이 완료되면 $\mathrm{RDF}$ 문서에 추가한다. $\mathrm{SQL}$ 질의문 결과 데이터의 변환이 완료된다.

Table 5. RDB to RDF Translator

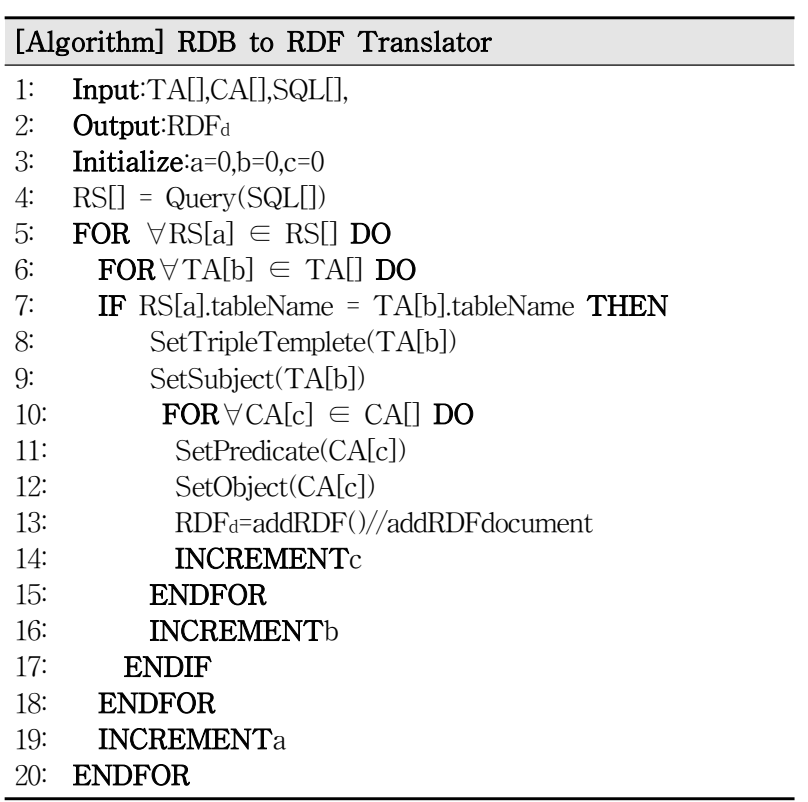

\section{$3.2 \mathrm{RDB}$ to $\mathrm{RDF}$ 변환 프로세스}

Fig. 2는 제안 시스템의 $\mathrm{RDB}$ to $\mathrm{RDF}$ 변환 프로세스를 나타낸다. 제안 시스템은 RDB to $\mathrm{RDF}$ a매퍼, R2RML 분석 기, $\mathrm{SQL}$ 생성기, $\mathrm{RDB}$ to $\mathrm{RDF}$ 변환기를 가진다. 매퍼는 Generator 함수를 이용하여 관계형 데이터베이스 구성요소 와 $\mathrm{RDFS}$ 구성 요소와의 매핑 규칙을 정의한다. R2RML 분 석기는 정의된 매핑 규칙을 사용하여 파싱 함수를 통해 $\mathrm{R} 2 \mathrm{RML}$ 에 정의된 정보를 설정한다. 이때 SetTableAttr 함수 와 SetColumnAttr 함수를 사용한다. 다음으로 AddTableAttr, AddColumnAttr 함수를 사용하여 관련 정보를 저장한다. $\mathrm{R} 2 \mathrm{RML}$ 에 정의된 정보의 분석이 끝나면 $\mathrm{SQL}$ 생성기는 $\mathrm{SQL}$ 질의문 생성을 시작한다. SQL 질의문을 Select, From 절로 구분하며 R2RML의 분석 정보를 이용하여 Select, From 절을 정의한다. 또한 R2RML에 정의된 기본 키, 외래 키 정보를 설정한다. 위와 같은 과정을 통해서 $\mathrm{SQL}$ 문을 생성하며 관계형 데이터베이스에 저장된 데이터를 질의한 다. 마지막으로 $\mathrm{RDB}$ to $\mathrm{RDF}$ 변환기는 $\mathrm{SQL}$ 질의문을 통해 얻은 결과를 바탕으로 $\mathrm{RDF}$ 를 생성한다. 이 때 테이블 명, 컬럼 명 사이의 관계정보가 R2RML에 정의되어 있으면 정 의된 정보를 바탕으로RDF를 추가로 생성한다. R2RML에 정의된 모든 트리플사상의 변환이 완료되면 $\mathrm{RDB}$ to $\mathrm{RDF}$ 변환 프로세스를 마친다.

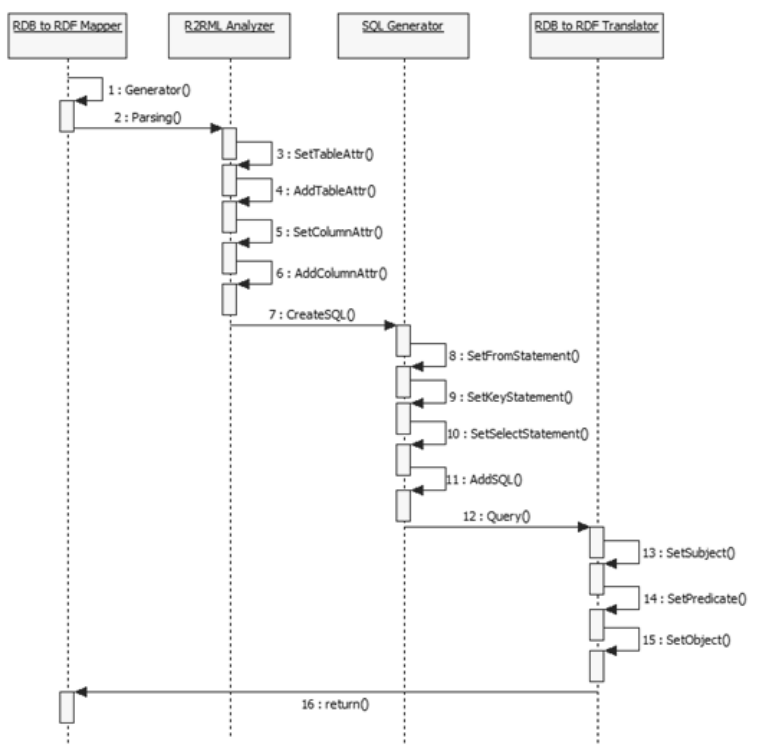

Fig. 2. Sequence Diagram for RDB to RDF Translation

\section{4. 구현}

이 장에서는 제안 시스템의 구현 환경과 구현 내용을 보 인다. 제안 시스템은 Windows 7 Enterprise K, Inter(r) Core(TM)2 Duo 2.66Hz, 3.25 GB Memory, JRE 1.7.0_15, MySQL 5.613, Eclipse Indigo 로 구성된 환경에서 수행하였 다. 제안 시스템을 실험하기 위해 온톨로지 생성도구 인 UBA(Univ-Benchmark Artificial Data Generator)를 이용하 여 온톨로지 데이터를 생성한다[23]. 또한 $\mathrm{UBA}$ 로부터 생성 되는 온톨로지를 관계형 데이터베이스에 동일하게 생성한 다. 이렇게 생성된 데이터는 제안 시스템과 기존 연구들의 성능을 비교하는데 사용된다.

\subsection{R2RML 분석}

Fig. 3은 제안 시스템에서 사용한 R2RML 예제를 나타낸 다. R2RML은 관계형 데이터베이스 테이블을 트리플사상에 매핑하여 구현한다. 위에 정의한 매핑 규칙에 따라 관계형 데이터베이스에 존재하는 수만큼 트리플사상이 생성된다. 트리플사상 내 논리테이블에는 관계형 데이터베이스 테이블 명 정보가 존재한다. 따라서 논리테이블 정보를 사용하여 관계형 데이터베이스 테이블 명 정보를 얻는다. 다음으로 주어사상에는 주어를 표현할 rr:template을 정의한다. 주어사 상에서 정의한 rr:template에 따라 주어는 표현된다. 또한 rr:template은 관계형 데이터베이스 테이블의 기본 키 정보 를 가지고 있다. rr:template에 존재하는 \{\} 안에는 해당 트 리플사상에서 사용할 기본 키 정보가 저장되어 있다. 테이 블 명, 기본 키 명, rr:template정보와 테이블 명은 $\mathrm{TA}[]$ 에 저장된다. $\mathrm{TA}[]$ 는 트리플사상에 대응되기 때문에 관계형 데 이터베이스 내 테이블 수만큼 테이블 속성 정보를 가진다. 마지막으로 술어목적어사상은 술어와 목적어 정보를 가지고 
있다. $\mathrm{RDF}$ 의 술어에 표현할 정보를 술어에 표현하며 실제 컬럼 명은 목적어에 rr:column 태그를 사용하여 표현한다. 따라서 술어에 표현된 정보가 실제 $\mathrm{RDF}$ 의 술어에 표현되며 $\mathrm{RDF}$ 의 목적어에는 컬럼 값이 표현된다. 제안 시스템은 관 계형 데이터베이스 스키마외에 $\mathrm{RDFS}$ 속성을 지원한다. 따 라서 술어목적어사상에는 RDFS 속성을 추가할 수 있다. 예 를 들어 rdfs:member 정보를 추가하기 위해서는 술어목적어 사상에 해당 정보를 추가하면 된다. Fig. 3은 rdfs:member 정보를 추가한 예제를 나타낸다. 술어에 rdfs:member를 표 현하면 제안 시스템은 해당 술어목적어사상은 RDFS 속성 정보를 표현한 것으로 판단하여 목적어를 컬럼 값이 아닌 $\mathrm{R} 2 \mathrm{RML}$ 의 목적어에 저장된 정보를 사용하여 표현한다. 이 렇게 생성된 술어목적어사상 정보는 $\mathrm{CA}[]$ 에 저장된다. $\mathrm{CA}[]$ 는 R2RML에서 정의한 술어목적어 수만큼 정의되며 $\mathrm{SQL}$ 질의문 생성과 $\mathrm{RDB}$ to $\mathrm{RDF}$ 변환을 위한 정보로 사용된다.

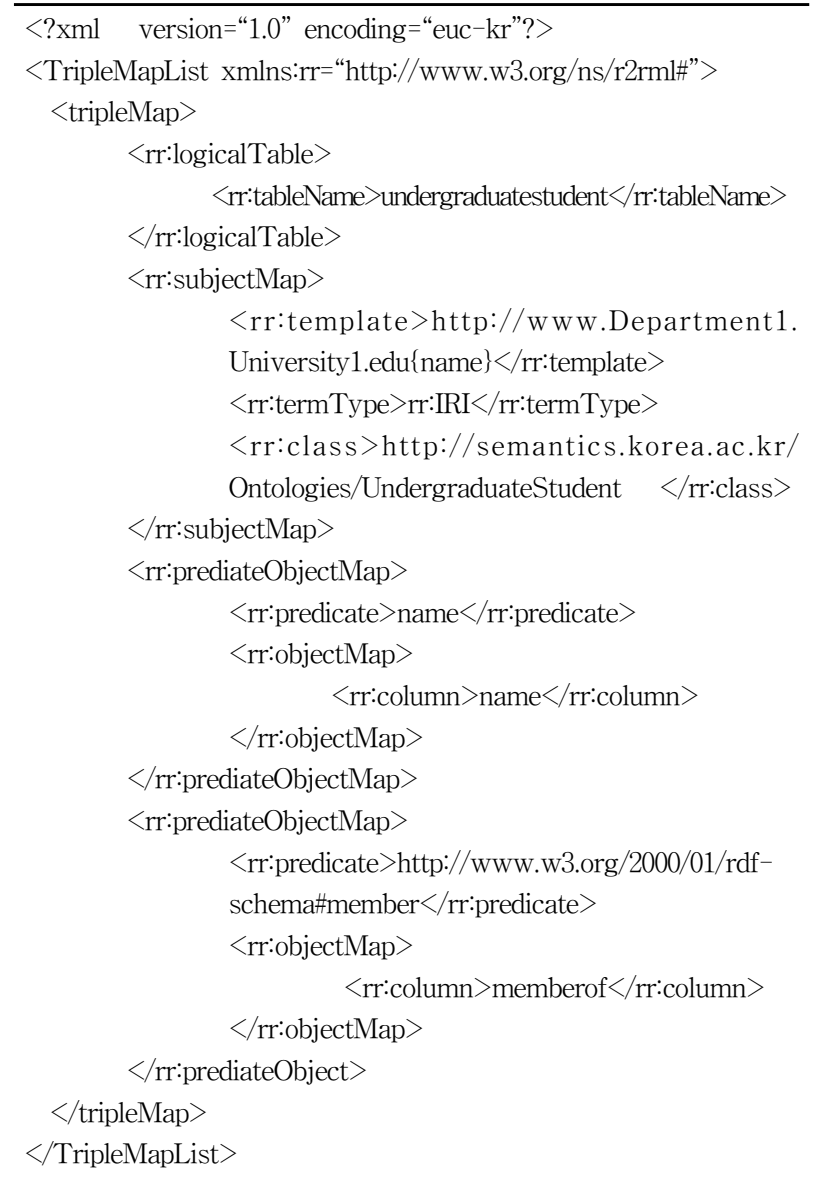

Fig. 3. An example of R2RML

\subsection{RDB to RDF 변환}

$\mathrm{R} 2 \mathrm{RML}$ 정보를 바탕으로 만들어진 $\mathrm{SQL}$ 질의문을 사용 하여 관계형 데이터베이스에 저장된 데이터에 접근한다. $\mathrm{SQL}$ 질의문을 통해 얻은 결과는 $\mathrm{RDB}$ to $\mathrm{RDF}$ 변환기 통해 $\mathrm{RDF}$ 로 변환된다. 이때, $\mathrm{TA}[], \mathrm{CA}[]$ 정보가 질의 결과를
$\mathrm{RDF}$ 로 변환하기 위해 사용된다. 질의 결과의 하나의 레코 드는 $\mathrm{TA}[]$ 를 통해 주어를 정의한다. 하나의 레코드는 생성 된 주어를 공유하며 술어와 목적어는 컬럼에 해당하는 CA[] 정보를 활용하여 정의한다. Fig. 3의 예제는 주어사상의 rr:template에 http://www.Department1.Universi tyl.edu\{name\} 로 정의되어 있다. 따라서 주어는 위 정보를 따르며 해당 레 코드의 기본 키 값이 name에 대치된다. 또한 술어목적어사 상에 정의된 규칙에 따라 술어와 목적어를 정의한다. Fig. 5 은 관계형 데이터베이스 스키마를 나타낸다. Fig. 4의 첫 번 째 레코드의 주어는 http://www.Department1.University1.edu/ UndergraduateStudent0으로 표현된다. 또한 rr:class 정보를 바탕으로 타입 정보를 설정한다. 각각의 컬럼 정보는 R2RML 에 정의된 정보에 따라 술어와 목적어로 변환된다. Fig. 5는 $\mathrm{R} 2 \mathrm{RML}$ 정보에 따라 변환된 결과를 나타낸다. 즉, Fig. 5는 Fig. 4의 데이터에 대한 온톨로지 변환 결과를 나타낸다.

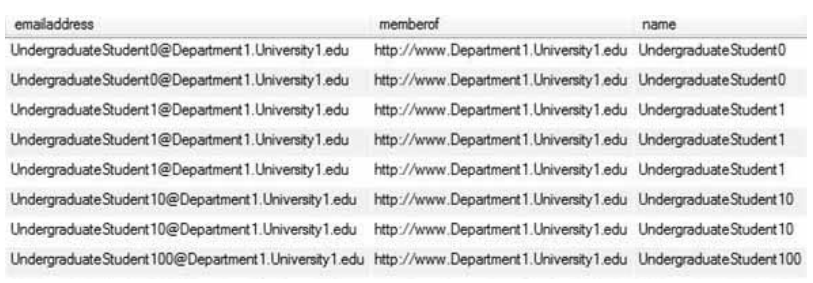

Fig. 4. Relational Database Schema

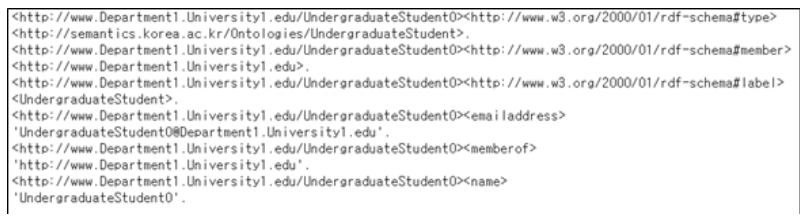

Fig. 5. Extracted ontology from a relational database

\section{3 구현 내용}

제안 시스템은 사전에 R2RML 정보를 만들어야 한다. $\mathrm{R} 2 \mathrm{RML}$ 정보는 접근하고자 하는 데이터베이스에 스키마 정 보를 기반으로 만든다. 사전에 만들어진 R2RML 정보는 파 싱 함수에 의해 $\mathrm{TA}[], \mathrm{CA}[]$ 정보를 저장한다. $\mathrm{TA}[]$ 와 $\mathrm{CA}[]$ 정보를 바탕으로 관계형 데이터베이스에 저장된 데이터를 가져오기 위해 $\mathrm{SQL}$ 질의문을 생성한다. $\mathrm{SQL}$ 질의문은 트 리플사상을 기반으로 생성한다. 따라서 트리플사상의 수만 큼 $\mathrm{SQL}$ 질의문이 만들어진다. 이렇게 만들어진 $\mathrm{SQL}$ 질의 문을 통해 관계형 데이터베이스에 저장된 데이터에 접근한 다. $\mathrm{SQL}$ 질의문의 결과는 $\mathrm{RDF}$ 변환을 위한 데이터로 사용 된다. R2RML에 정의된 규칙에 따라 질의 결과는 주어, 술 어, 목적어로 변환된다. 관계형 데이터베이스에 저장된 데이 터의 $\mathrm{RDF}$ 변환 시간은 $1 / 1,000$ 초 단위로 제공하여 시간에 대한 성능을 평가한다. 


\section{5. 실험 및 평가}

이 장에서는 $\mathrm{RDB}$ to $\mathrm{RDF}$ 변환 연구들에 대한 실험 결과 를 기술한다. 또한 이 논문에서 제안한 시스템과 기존 연구들 의 비교 분석을 통하여 정량적, 정성적 평가에 관해 기술한다.

정량 평가를 위하여 변환된 데이터의 크기와 데이터 변환 시간을 평가한다. 변환된 데이터의 크기는 제안 시스템과 다른 연구들의 변환 데이터의 크기 비교를 통하여 제안 시 스템의 온톨로지 변환 양을 비교한다. 데이터 변환 시간은 관계형 데이터베이스의 데이터를 $\mathrm{RDF}$ 로 변환하는 시간을 의미하며 제안 시스템의 성능을 평가한다. 제안 시스템과 비 교하기 위한 평가 대상으로는 $\mathrm{RDB}$ 에 저장된 데이터를 $\mathrm{RDF}$ 로 변환하기 위한 연구인 $\mathrm{D} 2 \mathrm{RQ}, \mathrm{RDBT}$ oOnto를 선정하였다. 또한 $\mathrm{R} 2 \mathrm{RML}$ 을 적용한 $\mathrm{RDB}$ to $\mathrm{RDF}$ 변환 연구인 Morph를 평가 대상으로 선정하였다. 실험을 위해 $\mathrm{D} 2 \mathrm{RQ}, \mathrm{RDBT}$ oOnto, Morph, 제안 시스템은 동일한 관계형 데이터베이스에서 구 현하였다. 데이터 생성은 UBA 온톨로지 생성기를 이용하였 으며, 총 50,000 개의 튜플을 관계형 데이터베이스에 저장하 였다. 또한 모든 비교 실험은 윈도우 시스템에서 실행하였 으며 관계형 데이터베이스는 MySQL을 사용하였다.

\section{1 정량 평가}

관계형 데이터베이스에 저장된 데이터를 $\mathrm{RDF}$ 형태의 온 톨로지로 변환하는 양의 크기를 비교하기 위해 RDB to $\mathrm{RDF}$ 변환 데이터의 크기를 비교한다. 실험을 위해 총 10 개 의 관계형 데이터베이스 저장소를 생성하였다. 각 데이터베 이스에는 데이터 크기를 5,000 개 튜플 단위로 추가하여 총 50,000 개 튜플을 저장하였다. Fig. 6은 제안 시스템에 관계형 데이터베이스의 테이블 명, 컬럼 명 사이에 관계정보를 추 가한 변환 결과를 나타낸다. $\mathrm{D} 2 \mathrm{RQ}$ 와 RDBToOnto의 경우에 는 자동으로 추가하는 $\mathrm{RDFS}$ 속성 정보를 포함한 결과를 나타낸다. D2RQ와 RDBToOnto는 Morph보다 변환 데이터 가 많았다. 관계형 데이터베이스에 저장된 데이터가 동일하 지만 데이터 변환 결과가 다른 이유는 $\mathrm{D} 2 \mathrm{RQ}$ 는 레이블 속성 을 변환 데이터에 자동으로 추가하기 때문이다. 또한 RDBToOnto는 RTAXON 학습 방법을 통해 지정된 단어의 경우 자체적으로 $\mathrm{RDFS}$ 속성을 추가하는 규칙을 가지고 있 다. 따라서 관계형 데이터베이스의 스키마 정보만을 변환하 는 Morph에 비해 D2RQ와 RDBToOnto는 많은 변환 결과 를 보였다. 하지만 제안 시스템에 관계형 데이터 베이스의 관계 정보를 추가할 경우에는 제안 시스템이 가장 많은 양 의 온톨로지를 생성하는 것을 보였다. 또한 제안 시스템은 매핑 정보에 추가 할 수 있는 $\mathrm{RDFS}$ 속성 종류가 많다. 따 라서 제안 시스템에 관계형 데이터베이스의 관계 정보를 추 가할 경우 다른 연구보다 많은 양의 변환 데이터를 생성하 는 것을 보인다.

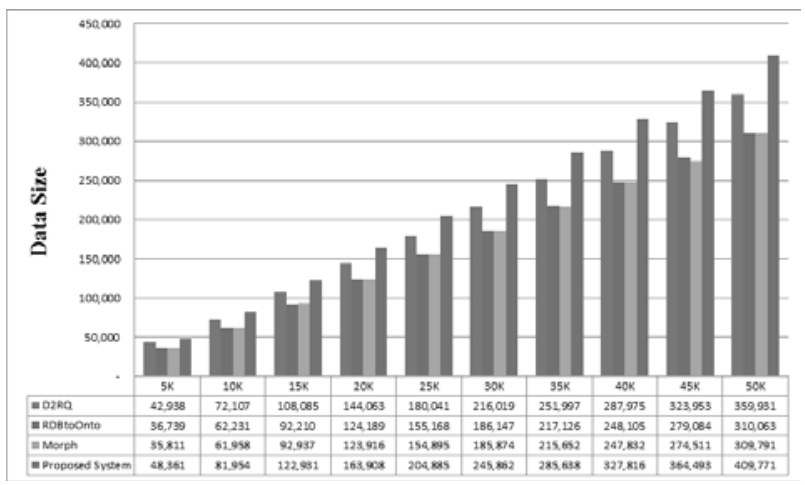

Fig. 6. Result of RDB to RDF Translation

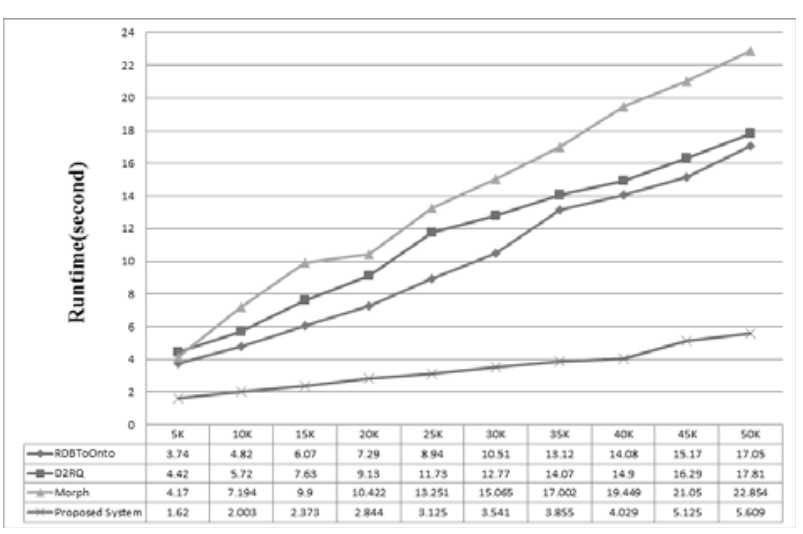

Fig. 7. Comparison of RDB to RDF Translation time

시스템의 성능을 평가하기 위해 $\mathrm{RDB}$ to $\mathrm{RDF}$ 변환 시간 을 비교한다. 변환 시간은 매핑 파일을 작성하는 단계는 고 려하지 않는다. Fig. 7는 관계형 데이터베이스에 저장된 데 이터를 $\mathrm{RDF}$ 형태의 온톨로지로 변환하는 시간에 대한 비교 결과를 나타낸다. D2RQ, RDBToOnto, Morph, 제안 시스템 을 이용하여 관계형 데이터베이스에 저장된 데이터를 $\mathrm{RDF}$ 형태의 온톨로지로 변환하는 데 걸리는 시간을 튜플의 개수 에 따라 측정하였다. Fig. 7은 제안 시스템이 다른 연구에 비해 가장 빠른 처리 시간을 갖는 것을 보인다. 따라서 제 안 시스템은 데이터 변환시간에서 다른 연구에 비해 우수한 성능을 갖는 것을 보인다.

\section{2 정성적 평가}

5.1절에서는 제안 시스템과 기존의 연구들의 $\mathrm{RDB}$ to $\mathrm{RDF}$ 변환 시간과 데이터 변환 결과를 비교하였다. 이 절에 서는 기존 연구와 제안 시스템의 정성적 평가를 통해 성능 비교 평가를 수행한다. $\mathrm{RDB}$ to $\mathrm{RDF}$ 변환에 대한 기존 연구 들과 제안 시스템의 비교 분석 결과는 Table 6에 나타낸다. 
Table 6. A comparative view of RDB to RDF mapping model

\begin{tabular}{c|c|c|c|c}
\hline Model & $\begin{array}{c}\text { Speed of } \\
\text { Mapping } \\
\text { Generation }\end{array}$ & $\begin{array}{c}\text { Reusability } \\
\text { of Mapping } \\
\text { Info }\end{array}$ & $\begin{array}{c}\text { Accessibility } \\
\text { of Mapping } \\
\text { Info }\end{array}$ & $\begin{array}{c}\text { Extension } \\
\text { of } \\
\text { ontology }\end{array}$ \\
\hline D2RQ & high & middle & middle & high \\
\hline RDBToOnto & high & low & low & middle \\
\hline Morph & middle & high & high & low \\
\hline $\begin{array}{c}\text { Proposed } \\
\text { System }\end{array}$ & middle & high & high & high \\
\hline
\end{tabular}

매핑 생성 속도는 매핑 정보 생성시 소요되는 시간을 구 분하기 위한 평가 요소이다. 매핑 정보생성 방식은 자동, 반 자동, 수동방식으로 구분되며 자동 생성 방식이 가장 우수 하다. 하지만 관계형 데이터베이스 스키마 정보만을 변환하 는 단점을 가진다. $\mathrm{D} 2 \mathrm{RQ}$ 와 $\mathrm{RDBToOnto}$ 는 매핑 정보를 자 동으로 생성하는 반면 제안 시스템과 Morph는 매핑 정보를 수동으로 생성한다. 따라서 $\mathrm{D} 2 \mathrm{RQ}$ 와 RDBToOnto가 매핑 정 보 생성에서는 우수한 성능을 보인다. 매핑 언어의 재사용 성은 시스템 독립적인 매핑 언어 사용 여부를 보여주는 평 가 요소이다. 시스템 종속적인 매핑 언어를 사용하면 매핑 언어에 대한 이해가 필요하다. 따라서 시스템마다 다른 매 핑 언어의 사용은 매핑 언어 사용의 재사용성을 떨어트린 다. $\mathrm{D} 2 \mathrm{RQ}$ 와 $\mathrm{RDBToOnto}$ 는 각각의 매핑 언어를 사용하며 Morph와 제안 시스템은 R2RML을 사용한다. 이와 같은 이 유로 Morph와 제안 시스템은 매핑 언어의 재사용성이 높다. 매핑 언어의 접근성은 표준화된 매핑 언어 사용 여부를 보 여주는 평가 요소이다. Morph와 제안 시스템은 표준화된 매 핑 언어를 사용하여 매핑 언어의 접근성이 높다. 또한 표준 화된 매핑 언어의 사용으로 매핑 언어에 학습에 들어가는 비용이 적다. 마지막으로 온톨로지 확장성은 변환 된 온톨 로지에 관계형 데이터베이스의 테이블 명, 컬럼 명 사이에 관계 정보를 추가할 수 있는지 여부를 확인할 수 있는 평가 요소이다. 제안 시스템은 매핑 정보를 수정하여 관계형 데 이터베이스의 테이블 명, 컬럼 명 사이에 관계정보에 대한 온톨로지를 추가하는 장점을 가진다. 이는 $\mathrm{D} 2 \mathrm{RQ}$ 와 동일한 기능이며 Morph에서는 지원하지 않는 기능이다. 따라서 제 안 시스템은 $\mathrm{D} 2 \mathrm{RQ}$ 와 같은 우수한 성능을 보이며 표준화된 매핑 언어 사용을 통해 높은 매핑 정보의 접근성과 재사용 성을 가진다.

\section{6. 결 론}

시맨틱 윕 환경에서 기존의 웹에 저장된 데이터에 접근을 위해 많은 연구가 이루어져 왔다. 기존 윕에 저장된 데이터 구조는 시맨틱 웹에서 사용하는 데이터 구조와 다르게 구성
되어 있다. 서로 다른 데이터 구조로 인해 시맨틱 웹에서는 기존 웹에 저장된 데이터를 이용할 수 문제점을 가진다. 하 지만 기존의 웹에 저장된 데이터를 버리고 새로운 시맨틱 웹 데이터를 구축하는 것은 많은 시간과 비용을 초래한다. 따라서 기존 웹에 저장된 데이터를 시맨틱 웹 환경에 맞게 변환하는 방법의 필요성이 대두되었다. 대부분의 변환 방법 은 매핑 방식을 이용하여 관계형 데이터베이스 구성요소와 $\mathrm{RDF}$ 구성요소를 연결하는 방식을 사용한다. 하지만 매핑 언어의 표준화가 이뤄지지 않아 시스템마다 다른 매핑 언어 를 사용하였다. 따라서 $\mathrm{W} 3 \mathrm{C}$ 에서는 매핑 언어의 표준을 위 해 R2RML을 제안하였다. 하지만 R2RML은 관계형 데이터 베이스의 테이블명, 컬럼명, 저장된 데이터를 온톨로지로 변 환하지는 않는다. 따라서 관계형 데이터베이스에 저장된 데 이터를 단순히 $\mathrm{RDF}$ 로 변환하는 것에 그친다. 풍부한 의미 정보가 있지 않은 온톨로지는 사용에 제한적이다.

이 논문에서는 관계형 데이터베이스 구성 요소의 의미 관 계를 고려한 $\mathrm{RDB}$ to $\mathrm{RDF}$ 매핑 시스템을 제안하였다. 제안 시스템은 R2RML을 매핑 언어로 사용하며 R2RML에 저장 된 정보를 이용하여 $\mathrm{SQL}$ 질의문을 생성한다. 위와 같이 생 성된 $\mathrm{SQL}$ 질의문을 통해 관계형 데이터베이스에 저장된 데 이터에 접근한다. $\mathrm{SQL}$ 질의문을 통해 얻은 관계형 데이터 베이스에 저장된 데이터는 R2RML의 정해진 규칙에 따라 $\mathrm{RDF}$ 로 변환된다. 제안 시스템은 추가적으로 R2RML에 $\mathrm{RDFS}$ 속성을 추가하여 데이터의 풍부한 의미 표현을 지원 하였다. 제안 시스템에 대한 평가로 정량평가와 정성평가를 수행하였다. Morph, RDBToOnto, D2RQ를 비교 대상으로 선정하고, 변환된 데이터의 크기와 변환 시간을 측정하였다. 그 결과 제안 시스템은 신뢰성을 보장할 수 있으며 가장 빠 른 변환 시간을 보여 우수한 성능을 보였다. 또한 정성적 비교 평가의 결과로 수동으로 매핑을 생성해야 하지만 표준 화된 언어를 이용하여 매핑 정보에 높은 접근성과 재사용성 을 보였다. 마지막으로 관계형 데이터베이스의 테이블 명, 컬럼 명 사이에 관계 정보를 추가하여 높은 온톨로지 확장 성을 보였다.

\section{참 고 문 헌}

[1] Jeen Broekstra, Arjohn Kampman, Frank van Harmelen, "Sesame: A Generic Architecture for Storing and Querying RDF and RDF Schema," Springer-Verlag, Lecture Notes in Computer Science, Vol.LNCS 2342, pp. 54-68, 2002.

[2] Jena-A Semantic Web Framework for Java, http://jena.sourceforge.net

[3] Oracle, http://download.oracle.com/otndocs/tech/semantic_web/pdf/oradb_semantic_overview.pdf

[4] SDB, http://jena.hpl.hp.com/wiki/SDB 
[5] OWLJessKB : A Semantic Web Reasoning Tool, http://edge. cs.drexel.edu/assemblies/software/owljesskb

[6] Steve Harris, "SPARQL query processing with conventional relational database systems," Springer Verlag, Lecture Notes in Computer Science,Vol. LNCS 3807, pp. 235-244, 2005.

[7] Dongwon Jeong, Myounghoi Choi, Yang-Seung Jeon, Youn-Hee Han, Laurence T. Yang, Young-Sik Jeong, and Sung-Kook Han, "Persistent Storage System for Efficient Management of OWL Web Ontology," Springer-Verlag, Lecture Notes in Computer Science, Vol. LNCS 4611, pp.1089-1097, 2007.

[8] RDB2RDF, http://www.w3.org/2001/sw/rdb2rdf/

[9] S. S. Sahoo, W. Halb, S. Hellmann, K. Idehen, T.Thibodeau, S. Auer, and J. Sequeda, A. Ezzat, "A Survey of Current Approaches for Mapping of Relational Databases to RDF," Technical Report,2009.

[10] Cullot, N., Ghawi, R., Yetongnon, K., "DB2OWL: A Tool for Automatic Database-to-Ontology Mapping," In Proceedings of 15th Italian Symposium on Advanced Database Systems, pages 491-494, Torre Canne, Italy, 2007.

[11] Bizer C., Cyganiak, R.,"D2RQ-Lessons Learned," Position paper for the W3C Workshop on RDF Access to Relational Databases, Cambridge, USA,2007.

[12] R2RML, http://www.w3.org/TR/r2rml/

[13] Morph, http://github.com/jpcik/morph

[14] DB2Triples, http://github.com/antidot/db2triples

[15] A. Chebotko, S. Lu, H.M. Jamil, F. Fotouhi, "Semantics preserving SPARQL-to-SQL query translation for optional graph patterns," Technical Report TR-DB-052006-CLJF, Wayne State University,2006.

[16] R. Cyganiak, "A relational algebra for SPARQL," Technical Report HPL-2005-170, Hewlett-Packard Laboratories, 2005.

[17] S. Harris, N. Shadbolt, "SPARQL query processing with conventional relational database systems," in Proceedings of the International Workshop on Scalable Semantic Web Knowledge Base Systems, pp. 235-244, 2005.

[18] Bizer, C. "D2R MAP-A Database to RDF Mapping Language," The twelfth international World Wide Web Conference, WWW2003, Budapest, Hungary, 2003.

[19] Prud'Hommeaux, Eric, and Andy Seaborne. "SPARQL query language for RDF," W3C recomm-endation 15, 2008.

[20] Bizer, C., Seaborne, "D2RQ-Treating Non-RDF Databases as Virtual RDF Graphs," in Proceedings of the Third International Semantic Web Conference, 2004.

[21] Fabrid Cerbah, "Learning Highly Structured Semantic Repositories from Relational Databases-The RDBToOnto Tool," in Proceedings of the 5th European Semantic Web
Conference, Tenerife, Spain, 2008.

[22] Cerbah. F. "Mining the Content of Relational Databases to Learn Ontologies with Deeper Taxonomies," in, Sydney, Australia, 2008

[23] Guo, Y., Pan, Z., and Heflin. J., "An Evaluation of Knowledge Base Systems for Large OWL Datasets," Springer Verlag, Third International Semantic Web Conference, Vol. LNCS 3298, pp. 274-288, 2004.

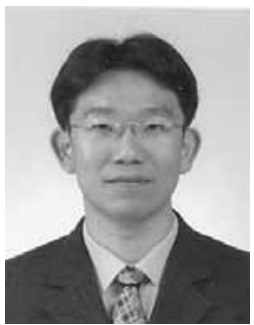

성 하 정

e-mail:octoom@korea.ac.kr

2006년 인하대학교 컴퓨터 공학과(학사)

2012년 현 재 고려대학교 컴퓨터·전파 통신공학과 석사과정

관심분야: 온톨로지, 시맨틱웹, 메타데이터 레지스트리

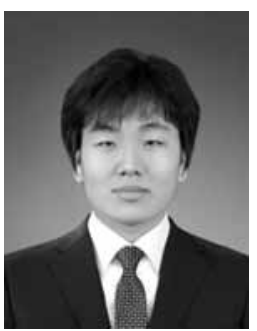

\section{김 장 원}

e-mail : jangwon@kisti.re.kr

2005년 상명대학교 소프트웨어공학과(학사)

2005년 한국과학기술연구원(KIST) 위촉연 구원

2008년 고려대학교 컴퓨터학과(이학석사)

2012년 고려대학교 컴퓨터 - 전파통신공학과 (공학박사)

2013년 현 재 한국과학기술정보연구원 선임연구원 관심분야: 온톨로지, 시맨틱 웹, GIS, 데이터베이스, 메타데이터, 지시적 분석 등

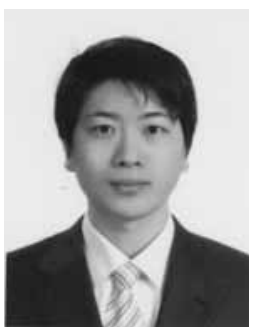

이 석 훈 e-mail : leha82@korea.ac.kr 2009년 고려대학교 전자 및 정보공학부 (학사)

2011년 고려대학교 컴퓨터·전파통신공학 과(공학석사)

2011년 현 재 고려대학교 컴퓨터·전파 통신공학과 박사과정

관심분야: 온톨로지, 데이터마이닝, 메타데이타 레지스트리, 자율 컴퓨팅 등 


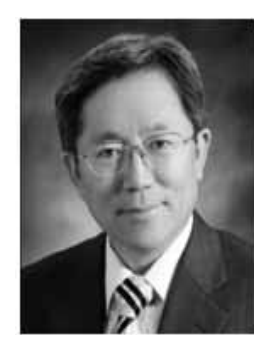

백 두 권

e-mail : baikdk@korea.ac.kr

1974년 고려대학교 수학과(학사)

1977년 고려대학교 산업공학과(석사)

1983년 Wayne State Univ. 전산학과(석사)

1985년 Wayne State Univ. 전산학과(박사)

1986년 2013년 고려대학교 컴퓨터·전파

통신공학과 교수

1989년 1991년 고려대학교 전산과학과 학과장

1990년 1991년 미국 Arizona대학교 객원 교수

1991년 2013년 ISO/IEC JTC1/SC32 전문위원회 위원장

1993년 1999년 한국과학기술원 객원책임연구원

1993년 1999년 한국DB진흥센터 표준연구위원

1996년 1997년 고려대학교 컴퓨터과학기술연구소(초대소장)

1997년 1998년 고려대학교 정보전산원 원장

1998년 1999년 한국정보과학회 전산교육연구회 운영위원장

1999년 2001년 정보통신진흥협회 데이터기술위원회 의장

2002년 2004년 고려대학교 정보통신대학(초대학장)

2002년 2003년 한국시뮬레이션학회 회장

2003년 현 재 정보통신부 컴퓨터프로그램보호위원회 위원

2004년 2005년 한국정보처리학회 부회장

2005년 2008년 한국소프트웨어진흥원 이사

2009년 2010년 고려대학교 정보통신대학 학장

2013년 현 재 고려대학교 융합소프트웨어전문대학원 교수

2013년 현 재 ISO/IEC JTC1/SC32 전문위원회 전문위원

관심분야: 메타데이터, 소프트웨어공학, 데이터공학, 컴포넌트기

반 시스템, 메타데이터 레지스트리, 프로젝트 매니지 먼트 등 